\title{
Aransemen Ansambel Woodwind Sebagai Identitas Orkes Keroncong Gita Puspita di Tegal
}

\author{
Meizan Riza Arhamni ${ }^{1}$; Abdul Rachman ${ }^{2}$ \\ 1,2 Pendidikan Sendratasik Universitas Negeri Semarang, Semarang, Indonesia \\ ${ }^{(*)} \bowtie$ (e-mail) jokosarjono2013@gmail.com; dulkmplinx@mail.unnes.ac.id
}

\begin{abstract}
Abstrak
Orkes Keroncong Gita Puspita merupakan salah satu orkes keroncong yang mendapat tempat di hati masyarakat kabupaten Tegal. Hal itu terjadi bukan secara instan, Orkes Keroncong Gita Puspita selalu berproses dalam berkarya dan berkreativitas sehingga berhasil mendapatkan tempat di hati masyarakat kabupaten Tegal khususnya para remaja. Salah satu keunikan Orkes Keroncong Gita Puspita adalah menggunakan ansambel woodwind ke dalam musik keroncong, dimana kolaborasi semacam ini belum pernah ada sebelumnya di kabupaten Tegal. Penelitian ini bertujuan untuk mendeskripsikan penggunaan ansambel woodwind pada musik keroncong oleh Orkes Keroncong Gita Puspita di Tegal. Penelitian ini menggunakan metode kualitatif dengan pendekatan analisis musik, pengumpulan data melalui observasi, wawancara, dan studi dokumentasi. Hasil penelitian menunjukan bahwa penggunaan ansamble woodwind pada Orkes Keroncong Gita Puspita cukup penting dalam komposisi, karena woodwind ansamble berfungsi sebagai pengisi aksen, filler, blocking note, dan melody note hal inilah yang membuat woodwind ansamble memiliki peran penting dalam setiap aransmen Orkes Keroncong Gita Puspita.
\end{abstract}

Kata kunci: Aransemen; ansamble woodwind; keroncong; gita puspita

\begin{abstract}
The Keroncong Orchestra Gita Puspita Orchestra is one of the Keroncong Orchestras that has a place in the hearts of the people of Tegal Regency. This happened not instantaneously, Keroncong Orchestras Gita Puspita has always been in the process of working and being creative so that he managed to get a place in the hearts of the people of Tegal Regency, especially teenagers. One of the uniqueness of Keroncong Orchestras Gita Puspita is the use of woodwind ensembles for Keroncong music, where this kind of collaboration has never existed before in the Tegal district. This study aims to describe the use of woodwind ensembles in Keroncong music by Keroncong Orchestras Gita Puspita in Tegal. This study uses a qualitative method with a music analysis approach, data collection through observation, interviews, and documentation studies. The results showed that the use of the woodwind ensemble on Keroncong Orchestras Gita Puspita is quite important in composition, because the woodwind ensemble functions as an accent filler, filler, blocking note, and melody note, this is what makes the woodwind ensemble have an important role in every Keroncong Orchestras Gita Puspita arrangement.
\end{abstract}

Keywords: Arrangement; woodwind ansamble; keroncong; gita puspita.

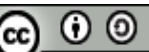

This work is licensed under a Creative Commons Attribution-ShareAlike 4.0 International License. Copyright (C) 2021 Meizan Riza Arhamni; Abdul Rachman

\section{Proses Artikel}

Diterima 14-09-2021; Revisi 17-12-2021; Terbit Online 19-12-2021 


\section{Pendahuluan}

Musik keroncong merupakan salah satu bentuk budaya bangsa Indonesia yang menjadi bagian penting bagi seluruh masyarakat pendukungnya. Musik keroncong telah lama sangat lama menjadi bagian dari masyarakat Indonesia yang di dalamnya terdapat nilai-nilai budaya yang menjadikan musik ini berkarakter dan berbeda dengan jenis musik lainnya (Henry, 2017). Munculnya musik keroncong di Indonesia seringkali dikaitkan dengan kedatangan bangsa Portugis pada abad ke 16, dimana waktu itu bangsa portugis datang ke Indonesia dengan misi perdagangan dan kedatangan bangsa Portugis tersebut tentunya secara tidak langsung juga membawa budaya yang lama-kelamaan berakulturasi dengan budaya Indonesia (Ganap, 2006, 2011, 2020; Harmunah, 1987, 1996; Wijayadi, 2007). Selain itu, beberapa sumber yang lain juga menuliskan bahwa musik keroncong merupakan kategori musik country yang kemudian berkembang ke seluruh pelosok tanah air melalui para pelaku seni ataupun praktisi musik dimana musik ini dianggap mampu menangkap fenomenafenomena dan juga mensosialisasikan kearifan lokal ke tingkat global. Dengan demikian musik keroncong sering sekali beradaptasi dengan jenis-jenis musik yang lain baik musik tradisi maupun musik barat (Ferzacca, 2015; Ferzacca et al., 2012; Rachman \& Utomo, 2019).

Sejak munculnya di Indonesia hingga sekarang musik keroncong tentu saja mengalami banyak dinamika. Musik keroncong mengalami era keemasan pada abad 20 yang ditandai dengan munculnya para tokoh, komponis, dan praktisi musik keroncong yang disebut "Buaya Keroncong", maraknya kompetisi/lomba cipta lagu dan menyanyi keroncong baik di tingkat lokal maupun berskala nasional yang diselenggarakan secara rutin setiap tahun, hingga banyaknya pertunjukan musik keroncong di media seperti radio dan televisi yang diselenggarakan secara reguler (Ganap, 2011, 2020; Harmunah, 1987; Rachman, Abdul; Lestari, 2012; Rachman, 2013b). Akan tetapi pada abad 21 seiring dengan era globalisasi dan perkembangan teknologi informasi yang sangat massive eksistensi musik keroncong mulai goyang keberadaannya di masyarakat. Berubahnya pola konsumsi masyarakat terhadap segala jenis informasi seperti mudahnya mengakses budaya luar negeri, berita, film, musik dengan hanya menggunakan smart phone membuat budaya negeri sendiri semakin terkesampingkan terutama para remaja yang sudah sangat fimiliar dengan teknologi semacam ini. Era globalisasi ini juga menyebabkan banyak media seperti televisi, radio, surat kabar dan media elektronik yang lain semakin gencar menyajikan budaya-budaya luar seperti musik rock, pop, jazz, K-pop, India, Jepang dan lain-lain yang membuat musik-musik tradisi Indonesia termasuk musik keroncong semakin tidak mendapatkan tempat di hati masyarakat (Asriyani \& Rachman, 2019; Fauziah \& Rachman, 2017; Qurrata A'yun \& Rachman, 2019; Rachman et al., 2019; Rachman \& Pribadi, 2019; Rachman \& Utomo, 2018, 2019; Ramadhani \& Rachman, 2019a; Sulestiyorini, 2013).

Era globalisasi yang telah memasuki era baru yaitu revolusi industri 4.0 ini telah mendisrupsi berbagai aktivitas masyarakat di berbagai bidang seperti politik, ekonomi, sosial, bahkan hingga ke perkembangan industri musik yang semula manual menjadi digital. Perkembangan era revolusi indstri 4.0 yang tidak terbendung telah memberi pengaruh yang sangat besar terhadap aktivitas manusia yaitu pergeseran dari ativitas di dunia nyata ke aktivitas di dunia maya(Prasetyo \& Trisyanti, 2019; Ramadhani \& Rachman, 2019; Muhammad \& Rachman, 2020). Pada konteks musik keroncong banyak sekali para pelaku seni musik keroncong yang berusaha beradaptasi untuk mempertahankan budayanya agar bisa bertahan sesuai dengan tuntutan zaman. Upaya yang dilakukan diantaranya adalah 
dengan menginovasi musik keroncong dengan cara mengkolaborasikan berbagai genre musik lain seperti pop, jazz, ataupun blues, ska, reggae, cha-cha, samba, dan genre musik lainnya (Qurrata A'yun \& Rachman, 2019; Rachman \& Utomo, 2018, 2019; Setiyawan, 2018). Ada juga yang dilakukan oleh komposer musik keroncong yang bernama Kelly Puspito dengan cara melakukan inovasi terhadap melodi, harmonisasi, dan aransemen musiknya (Rachman, Abdul; Lestari, 2012; Rachman, 2013a).

Kabupaten Tegal merupakan salah satu kota di Jawa Tengah yang memiliki apresiasi yang tinggi terhadap musik tradisional. Musik tradisional yang berkembang di kabupaten Tegal diantaranya adalah dangdut, campursari, karawitan, terbangan, balo-balo, dan keroncong. Tiap musik tradisional tersebut memiliki penikmat musik yang berbeda-beda dari segala lapisan masyarakat. Seperti halnya musik keroncong yang eksis dan mendapat apresiasi yang cukup baik oleh masyarakat maupun pemerintah kabupaten Tegal. Tidak jarang pemerintah kabupaten Tegal bekerja sama dengan orkes-orkes keroncong untuk menyuarakan program pemerintah yang sedang dijalankan. Melalui musik keroncong dirasa mampu mengajak masyarakat untuk bersama-sama membangun kabupaten Tegal (lqbal et al., 2020; Ramadhani \& Rachman, 2019b).

Keberadaan dan perkembangan orkes keroncong di kabupaten Tegal cukup unik, salah satunya adalah Orkes Keroncong Gita Puspita. O.K Gita Puspita memiliki keunikan yaitu menyajikan musik keroncong dengan mengkolaborasikan antara musik keroncong dengan woodwind ansamble. Perpaduan antara keroncong dengan woodwind ansamble menghasilkan harmonisasi yang indah, adanya woodwind ansamble memiliki peran dalam setiap aransmen O. K Gita Puspita. Tanpa adanya woodwind ansamble aransmen dari O. K Gita Puspita terasa kurang karena banyak nada yang dimainkan oleh woodwind ansamble. Intrumen woodwind yang digunakan O. K Gita Puspita adalah flute, clarinet, alto saxophone dan tenor saxophone.

Berdasarkan fenomena tersebut artikel akan membahas tentang aransemen instrumen woodwind pada O. K Gita Puspita. Dari beberapa teori yang mendukung aransemen, penulis akan menganalisa penggunaan instrumen woodwind berdasarkan ekspresi yang meliputi aksen dan harmoni yang meliputi filler, melody note, dan blocking note. Untuk mendeskripsikan penggunaan instrumen woodwind pada O. K Gita Puspita, penulis menggunakan lagu model yang sering dibawakan dalam pentas yaitu lagu "Empat Cinta". Lagu "Empat Cinta" bertempo 114 dan mengalami perubahan tempo menjadi 122 pada bar 105. Lagu "Empat Cinta" bertanda birama 4/4 dengan nada dasar Bb mayor dan mengalami perubahan menjadi G mayor pada bar 153. Lagu “Empat Cinta” memiliki jumlah birama 172.

\section{Metode}

Metode penelitian yang digunakan adalah kualitatif dengan pendekatan analisis musik dengan merujuk Leon (1979) dan Prier (2005) yang menghasilkan data deskriptif tentang Aransemen Ansambel Woodwind sebagai Identitas Orkes Keroncong Gita Puspita di Tegal. Teknik pengumpulan data yaitu dengan observasi, wawancara, dan studi dokumentasi. Observasi dilakukan terhadap aransemen ansambel woodwind baik berupa dokumen maupun video pertunjukan, kemudian wawancara dilakukan kepada arranger musik untuk mengetahui hal-hal yang berhubungan dengan aransemen ansambel woodwind, sedangkan studi dokumentasi berupa partitur hasil aransemen untuk memahami, menganalisis, dan 
mendeskripsikan tentang aransemen tersebut. Teknik analisis data dilakukan dengan pengumpulan data, proses reduksi, klarifikasi, interpretasi data, dan penyajian data yan artinya data-data yang terkumpul kemudian direduksi untuk diambil data-data yang sesuai dengan penelitian kemudian dilakukan klarifikasi dan interpretasi yang selanjutnya untuk disajikan berupa pembahasan yang terkait dengan penelitian hingga dan penarikan kesimpulan.

\section{Hasil}

\section{Aransemen Instrumen Woodwind Pada Orkes Keroncong Gita Puspita di Tegal}

Orkes Keroncong Gita Puspita dikenal oleh masyarakat kabupaten Tegal dan sekitarnya karena berntuk musiknya yang berbeda dengan orkes keroncong yang lain, dimana salah satu karakteristik dari orkes keroncong ini adalah aransemen musiknya. Aransemen yang menjadi ciri khas dari Orkes Keroncong Gita Puspita yaitu adanya ansambel woodwind pada setiap penampilannya. Ansambel woodwind pada Orkes Keroncong Gita Puspita memiliki peran dalam dinamika dan harmoni. Yang mana woodwind ansamble memainkan aksen sebagai dinamika dan memainkan filler, melody note, dan blocking note sebagai harmoni. Pada bagian ini akan dibahas mengenai aransemen tersebut.

\section{Aransemen Melody pada Orkes Keroncong Gita Puspita}

Umumnya introduksi musik keroncong merupakan penggalan melodi dari lagu versi originalnya. Namun, O. K Gita Puspita membuat introduksi lagu "Empat Cinta" berbeda dengan melodi lagu versi original. Introduksi diawali dengan flute dan clarinet yang dimainkan secara canon, flute dan clarinet menciptakan motif-motif baru yang tidak terdapat dalam lagu.

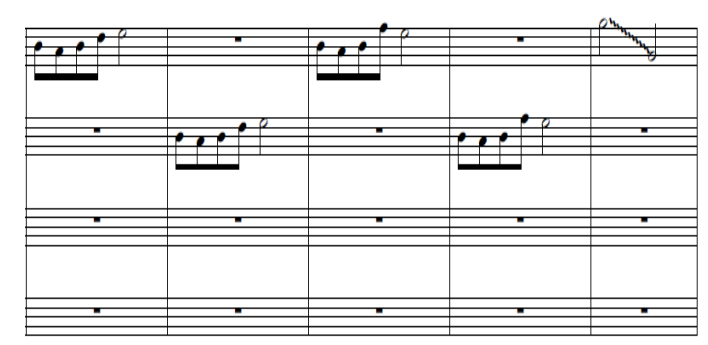

Partitur 1. Introduksi bar 8-11

(Sumber: Arhamni 2020)

Komposisi instrumen pada partitur 1 adalah dari atas ke bawah yaitu flute, clarinet, alto saxophone dan tenor saxophone. Bagian introduksi ini bagian awal menuju woodwind ansamble bermain secara bersamaan. Pada musik keroncong, flute berfungsi sebagai bukaan atau vrosphel, namun pada introduksi tersebut flute tidak memainkan vrosphel. Intro adalah bagian permulaan atau pembukaan (Kodijat, 1986, 2004). Intro semacam ini sudah tidak lagi bermain secara pakem, gaya garapan seperti ini masuk ke dalam keroncong ekstra. Keroncong ekstra merupakan lagu yang bukan dari lagu keroncong namun cara penyajiannya menggunakan alat-alat keroncong (Soeharto, 1996). Berdasarkan partitur 1 di atas bisa dilihat bahwa pada birama 8 - 9 flute dan clarinet memunculkan motif kalimat tanya yang dilakukan secara canon yaitu pada birama 8 instrumen flute memainkan rangkaian melodi $b-a-b-d$ - e yang diikuti oleh instrumen clarinet pada birama 9 memainkan rangkaian melodi yang sama yaitu $b-a-b-d-e$ kemudian kalimat tanya tersebut dijawab pada bar $10-11$ yaitu 
pada birama 10 instrumen flute memainkan rangkaian melodi $b-a-b-f-e$ yang diikuti oleh instrumen clarinet pada birama 11 dengan memainkan rangkaian melodi yang sama yaitu $b-a-b-f-e$.

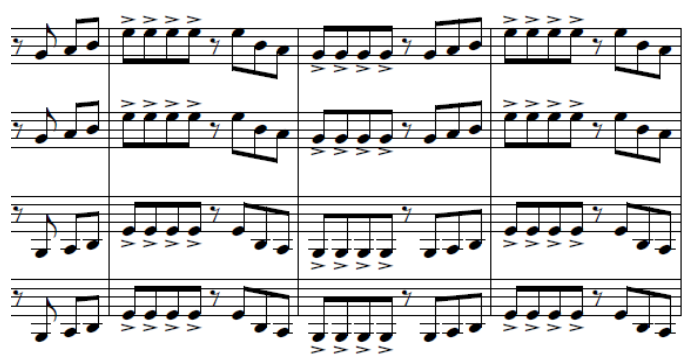

Partitur 2. Introduksi Unisono bar 16-20

(Sumber: Arhamni, 2020)

Berdasarkan partitur 2 di atas bisa dilihat bahwa instrumen flute, clarinet, alto saxophone dan tenor saxophone memainkan rangkaian melodi secara unisono. Unisono adalah bersatu, satu melodi dibawakan serentak oleh berbagai suara atau berbagai alat musik (Kodijat, 2004). Meskipun rangkaian melodi dimainkan secara unisono, akan tetapi timbre tiap instrumen tersebut jelaslah berbeda antara satu dengan yang lain, sehingga perpaduan dari warna suara yang berbeda-beda menghasilkan nuansa warna suara yang indah dan tidak keruh karena tidak dalam oktaf yang sama.

\section{Aransemen Nuansa Aksen pada Orkes Keroncong Gita Puspita}

Pada Partitur 2 juga terlihat bahwa woodwind ansamble berperan sebagai pengisi aksen untuk mempertegas nada yang dihasilkan. Sedangkan pada bar ke-20 bisa dilihat antara instrumen flute, clarinet, alto saxophone dan tenor saxophone dibagi menjadi empat suara yang membentuk akor Gm tanpa menggunakan kwintnya. Karena sifat dari kwint tidak memperlihatkan sifat akor, yang memperlihatkan sifat akor adalah terts.

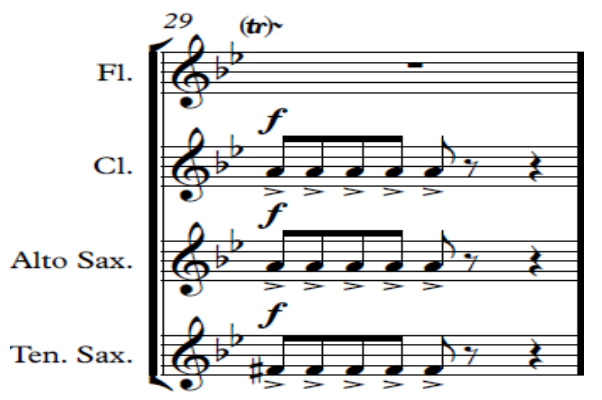

Partitur 3. Woodwind pengisi aksen bar 29 (Sumber: Arhamni, 2020)

Pada birama ke-29 di atas, woodwind ansambel memberi aksen untuk memberi tanda bahwa introduksi akan berakhir yang dilanjutkan dengan lagu. Dinamika pada birama tersebut dimainkan secara forte (keras) dan dilanjutkan dengan tanda aksen yang seolah-olah memberikan nuansa atau tanda kepada penyanyi untuk masuk pada bagian lagu. Hal ini mempermudah penyanyi untuk memjembatani sebelum masuknya lagu. Tenor saxophone berperan sebagai terts sedangkan clarinet dan alto saxophone berperan sebagai kwint, walau tanpa root harmonisasi dua suara tersebut tetap terasa nyaman karena root tetap dimainkan oleh bass keroncong. Jadi woodwind ansambel sebagai pengisi aksen berfungsi untuk mempermanis aransemen dari instrumentasi keroncong. 


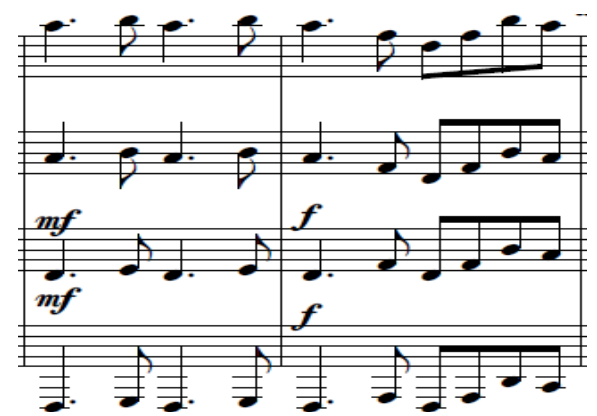

Partitur 4. Woodwind pengisi aksen bar 59-60

(Sumber: Arhamni, 2020)

Pada bar 59 woodwind ansambel memecah suara hingga empat suara dimana instrumen tenor saxopohone berperan sebagai root, alto saxophone sebagai root satu oktaf lebih tinggi dari tenor saxophone untuk memperkuat akor, clarinet sebagai kwint sedangkan flute sebagai kwint juga satu oktaf lebih tinggi dari clarinet. Berdasarkan partitur 4 di atas tidak terdapat tanda aksen, akan tetapi dinamika pada bagian tersebut cukup jelas yaitu dari mezzo forte menuju forte sehingga nuansa aksennya masih tetap muncul. Memasuki bar ke60 woodwind ansamble bermain secara unisono dengan oktaf yang berbeda, kecuali alto saxophone dan clarinet bermain di range suara yang sama. Harmoni tiga suara merupakan pengembangan dari harmoni dua suara. Harmoni tiga suara terbentuk dari triad dari melodi pokok lagu tersebut (Prier, 2005).

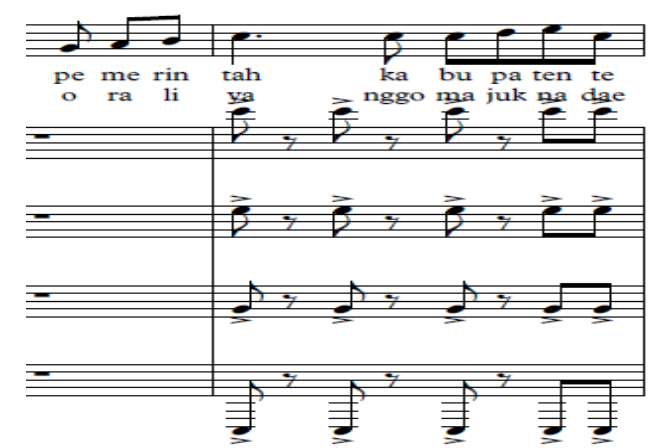

Partitur 5. Woodwind pengisi aksen bar 108-109 (Sumber: Arhamni, 2020)

Pada birama 108-109 di atas (Partitur 5) bisa dilihat bahwa woodwind ansambel memainkan rangkaian aksen ritmis yang mengimitasi dari ritmis musik dangdut ketika senggakan yaitu secara bersamaan memainkan ritmis rangkaian not $1 / 4$ secara staccato pada ketukan 1 sampai tiga kemudian pada ketukan keempat memainkan not 1/8an secara staccato. Hal ini menimbulkan kesan semangat dan menjadi tidak monoton karena iringannya tidak sama antara bagian satu dengan bagian dua. Ritmis semacam ini sangat baik dimainkan oleh woodwind, mengingat timbre dari woodwind yang memiliki volume cukup keras bila ditiup secara forte. 


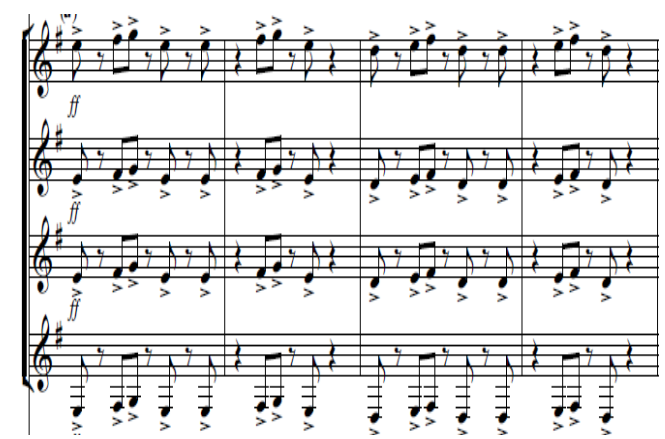

Partitur 6. Woodwind pengisi aksen bar 164-168 (Sumber: Arhamni, 2020)

Aksen yang menarik dari partitur 6 adalah terdapatnya aksen yang tidak berada di ketukan kuat (vorhalt) pada bar 165 dan 168. Ritmis seperti ini biasa disebut syncope, syncope berarti pemindahan tekanan dari bagian birama berat ke bagian birama ringan. Pemilihan nada pada bagian tersebut dimainkan secara unisono namun dengan oktaf yang berbeda, kecuali alto saxophone dengan clarinet yang berada pada oktaf yang sama. Kesan yang ditimbulkan dari ritmis dan aksen pada gambar enam adalah memberikan kejutan pada coda sebelum lagu tersebut berakhir.

\section{Aransemen Melodi Isian (Filler) pada Orkes Keroncong Gita Puspita}

Melodi isian (filler) pada Orkes Keroncong Gita Puspita dimainkan oleh flute dan clarinet dengan teknik broken chord yang membentuk akor lagu tersebut. Pada partitur 7 menunjukkan bahwa Pada bar 32 membentuk akor $\mathrm{C}$ sedangkan bar 33 membentuk akor $\mathrm{Gm}$. Broken chord adalah Trinada yang dimainkan berurutan gerak pendek. Permainan flute dan clarinet dimainkan secara stacato, ini adalah pilihan yang baik. Menurut Moordiana (1987), " Di antara alat-alat musik tiup dalam orkes, flute merupakan alat musik yang paling lincah dan sangat tangkas. Secara khusus stacato sangat sesuai untuk dimainkan oleh flute, karena memungkinkan adanya permainan lidah rangkap".

Nada-nada pada oktaf rendah dari flute kedengaran cukup manis, walaupun tidak terlalu kuat, nada-nada di atasnya menjadi sebaliknya, yaitu memiliki kualias suara yang cukup menusuk. Karena inilah flute kebanyakan dipergunakan untuk memainkan nada-nada tinggi dalam orkes (Moordiana, 1987).

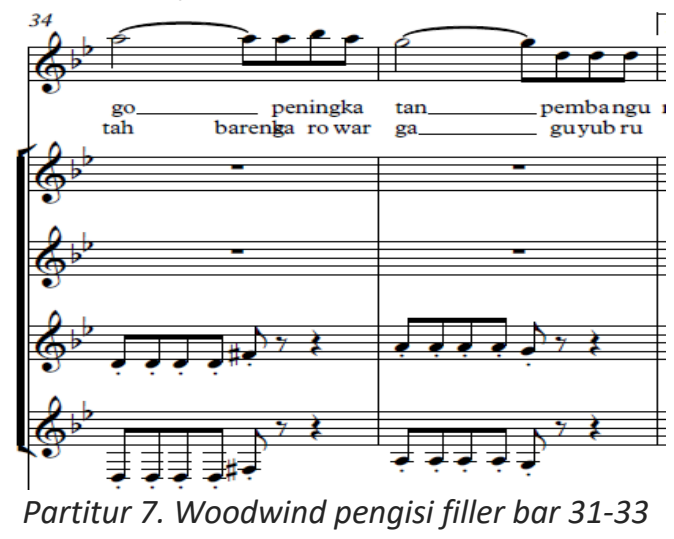

(Sumber: Arhamni, 2020) 
Pada partitur 8 isian melodi (filler) dimainkan oleh alto saxophone dan tenor saxophone secara unisono dengan oktaf yang berbeda, filler tersebut tidak menutupi melodi vokal karena melodi vokal dimainkan dengan harga not setengah kemudian diperpanjang seperdelapan sementara harga not pada alto saxophone dan tenor saxophone seperdelapanan tanpa legato ini berarti alto saxophone dan tenor saxophone mengisi kekosongan pada bar tersebut. Tenor saxophone dan alto saxophone menggunakan harmoni dua suara.

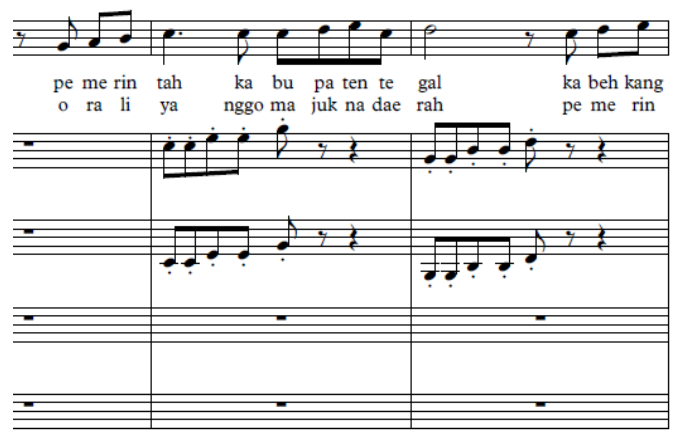

Partitur 8. Woodwind pengisi filler bar 34-35 (Sumber: Arhamni, 2020)

Pada partitur 9 instrumen flute memainkan melodi yang singkat, kesan dari melodi tersebut cukup terasa karena flute memainkan nada sisipan yang sedikit unik. Permainan flute menggunakan pendekatan kromatis dari c\#2 menuju d2, jadi sebelum nada yang dituju flute memainkan nada yang berjarak setengah sebelum nada tersebut. Walaupun menyimpang pada tangga nada $\mathrm{Do}=\mathrm{Bb}$, akan tetapi not tersebut tidak terasa fals.

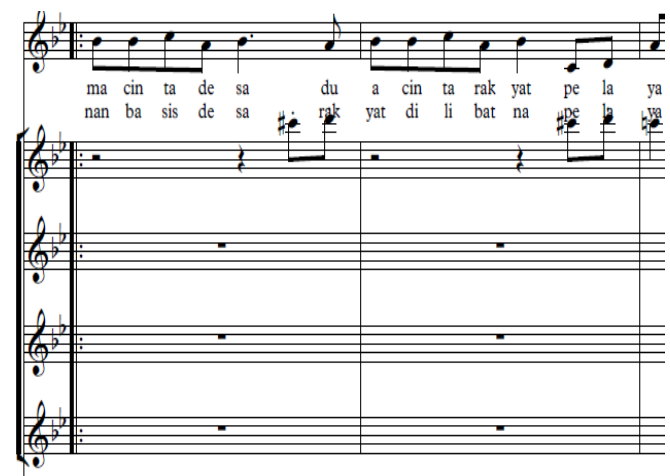

Partitur 9. Woodwind pengisi filler bar 42-43

(Sumber: Arhamni, 2020)

Pada partitur 10, woodwind mengisi isian melodi (filler) pada bar 139. Sama halnya dengan gambar 8, permainan woodwind berfungsi untuk mengisi kekosongan pada bar 139. Permainan woodwind tidak menutupi melodi vokal karena woodwind menggunakan harga not seperdelapan sedangkan melodi vokal menggunakan harga not seperempatan yang diperpanjang dengan seperdelapanan not. 


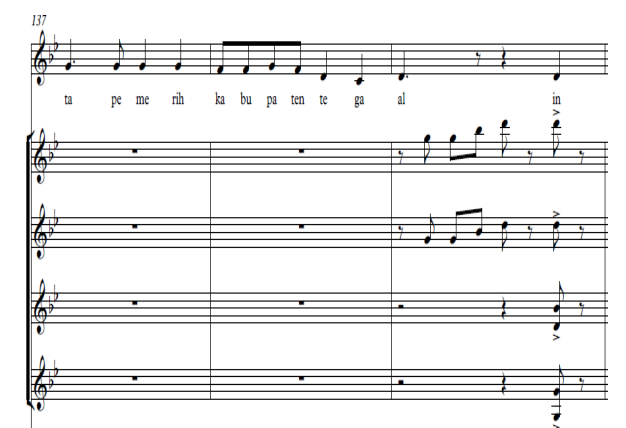

Partitur 10. Woodwind pengisi filler bar 137-139

(Sumber: Arhamni, 2020)

Pada partitur 11 di atas isian melodi (filler) dimainkan oleh flute dan clarinet dengan oktaf yang berbeda dan dimainkan secara stacato. Sama halnya dengan partitur 10, filler tersebut berfungsi untuk mengisi kekosongan pada bar 143. Bila kekosongan bar ini tidak diisi maka yang terjadi kejenuhan, terasa monoton. Diantara semua alat musik tiup, clarinet merupakan alat musik yang memiliki kemampuan paling besar untuk meningkatkan kekuatannya (Moordiana, 1987).

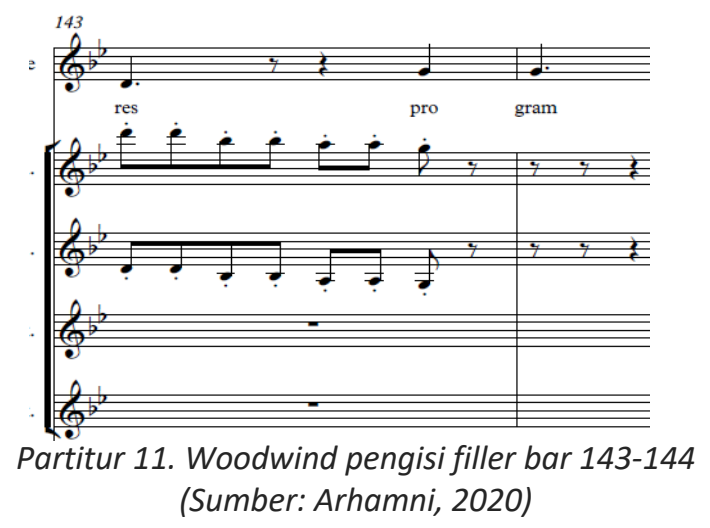

\section{Aransemen Blocking Note pada Orkes Keroncong Gita Puspita}

Tidak hanya string ansamble saja yang mampu memainkan blocking note, woodwind ansamble pun mampu melakukannya. Pada partitur 12 tenor saxophone memainkan nada root, alto saxophone sebagai terts sedangkan clarinet sebagai kwint. Namun flute tetap bergerak sebagai pengisi coda. Harmoni pada partitur 12 menggunakan posisi terbuka karena antara alto saxophone dengan clarinet bisa disisipi nada lain. Posisi terbuka secara warna akan menghasilkan warna suara yang terang dan terkesan luas dan megah, sehingga di dalam akhir lagu dianjurkan menggunakan posisi ini (Sinaga Syahrul, 2016: 55). Pergerakan harmoni diatas menyerupai bentuk sajian musik kwartet tiup, flute sebagai melodi utama sedangkan clarinet, alto saxophone dan tenor saxophone sebagai pengiring. 


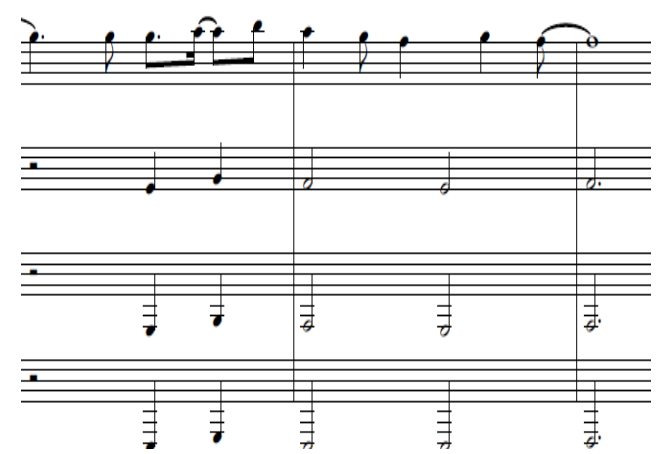

Partitur 12. Woodwind blocking note bar 22-24 (Sumber: Arhamni, 2020)

Pada partitur 13 birama ke-43, antara clarinet, alto saxophone dan tenor saxophone memainkan blocking note secara unisono. Hal ini memiliki maksud agar blocking dari woodwind tidak mengganggu pergerakan melodi vokal. Karena bila pergerakan dari woodwind ansamble terlalu banyak maka akan berdampak menutupi melodi vokal sebagai melodi utama (cantus firmus). Kesan keruh akan terjadi bila instrumen pengiring lebih dominan dari pada melodi utama.

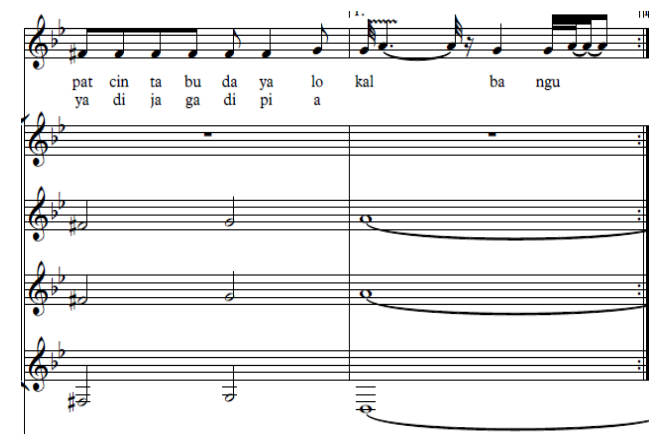

Partitur 13. Woodwind blocking note bar 43-44 (Sumber: Arhamni, 2020)

Pada partitur 14 pembagian suara pada ansambel woodwind terlihat lebih sederhana hanya terdiri dari dua suara saja. Pada bar 65 tenor saxophone sebagai root sedangkan alto saxophone dan clarinet sebagai terts. Pada bar 66 hampir sama dengan bar 65, yang membedakan adalah bentuk pembagian suara tersebut membetuk akor inversi, bar 66 akornya adalah Gm. Namun, yang menjadi root bukanlah tenor saxophone melainkan clarinet dan alto saxophone. Tenor saxophone berperan sebagai terts, ini adalah inversi akor pembalikan pertama. Posisi terts sebagai bass di dalam harmoni dinamakan first inversion atau pembalikan pertama, dimana nada terts berada dalam posisi root/bass (Sinaga Syahrul, 2016: 60). 


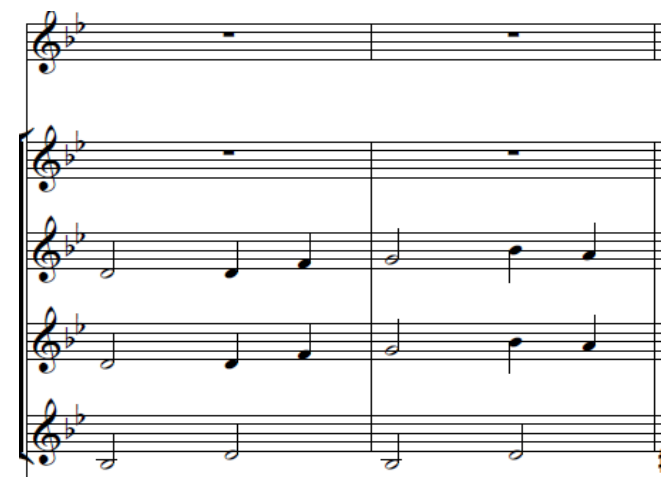

Partitur 14. Woodwind blocking note bar 65-66

(Sumber: Arhamni, 2020)

Pada partitur 15 terlihat bahwa yang memainkan melodi utama adalah instrumen flute. Sedangkan tenor saxophone, alto saxophone dan clarinet berperan sebagai blocking note. Tenor saxophone sebagai root, alto saxophone sebagai terts, dan clarinet sebagai kwint. Pergerakan harmoni seperti ini nyaman dimainkan karena, yang menjadi melodi utama adalah hanya satu intrumen sedangkan intrumen yang lain hanya memainkan not penuh.

Nada yang dimainkan tenor saxophone, alto saxophone dan clarinet berada diposisi yang aman karena tidak memainkan nada-nada penjarian di oktaf dua. Bila tenor saxophone, alto saxophone dan clarinet berada diposisi yang tidak seharusnya maka suara yang dihasilkan akan terasa kurang enak. Pemahaman tentang range suara tiap instrumen sangat diperlukan.

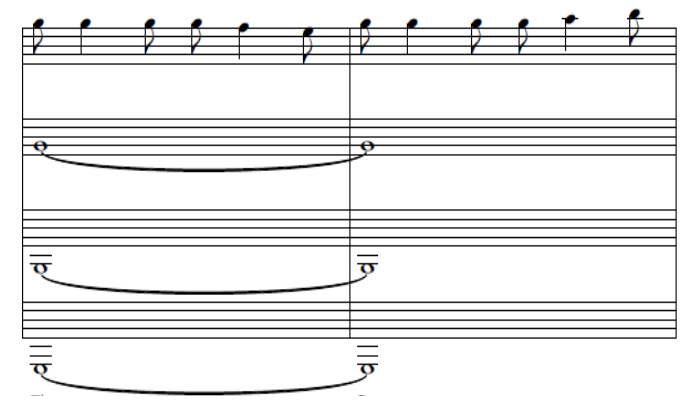

Partitur 15. Woodwindmelody note bar 25-26

(Sumber: Arhamni, 2020)

Pada partitur 16 woodwind ansamble berperan penting, karena pada bar 153 terjadi modulasi yaitu pergantian Nada dasar yaitu yang semula $\mathrm{Do}=\mathrm{Bb}$ menjadi $\mathrm{Do}=\mathrm{G}$. Yang awalnya Gm menjadi G, tanpa pergerakan melodi dari woodwind maka pesan modulasinya kurang terasa. Ini adalah salah satu bagian penting woodwind ansamble pada aransmen "Empat Cinta" yang dibawakan O. K Gita Puspita. Walau unisono namun suara yang dihasilkan tidak keruh karena antara tenor saxophone, alto saxophone, clarinet dan flute memiliki timbre suara yang berbeda. Adanya teknik slur menambah indah suara yang dihasilkan dari woodwind ansamble. 


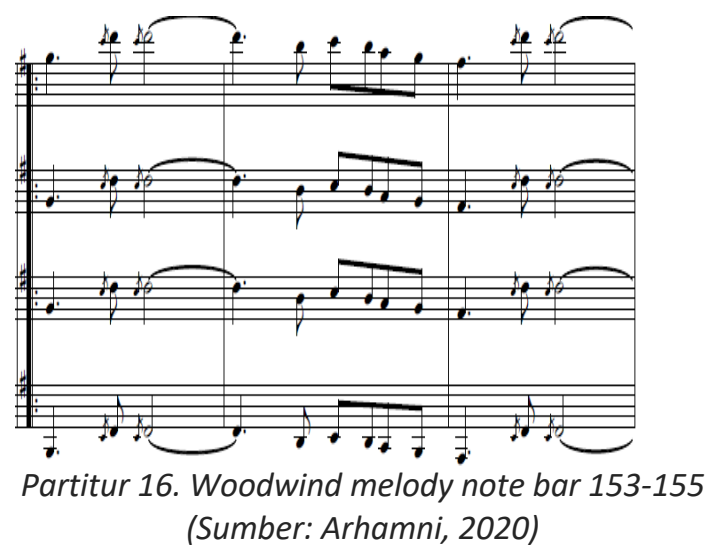

Sama halnya dengan partitur 16, pergerakan melodi yang dimainkan pada bar 160-163 masih tetap menggunakan teknik unisono. Namun pada akhir birama instrumen flute memainkan teknik trill, sehingga memberi warna suara yang baru agar tidak terdengar monoton.

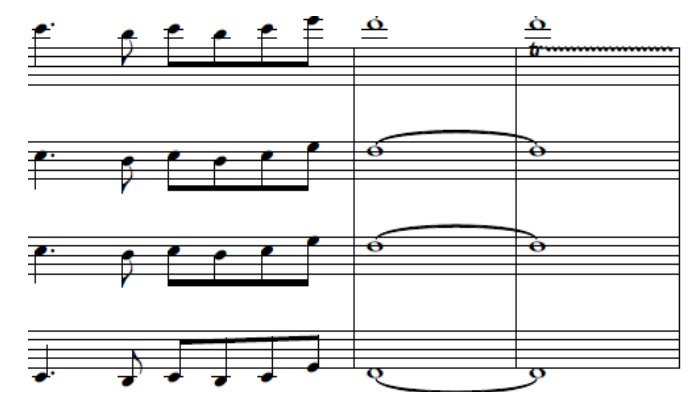

Partitur 17. Woodwind melody note bar 160-163 (Sumber: Arhamni, 2020)

\section{Kesimpulan}

Aransemen instrumen woodwind pada Orkes Keroncong Gita Puspita meliputi aransemen beberapa instrumen yaitu flute, clarinet, alto saxophone, dan tenor saxophone dimana teknik aransemen yang diterapkan adalah accent fill in yaitu permainan secara unisono yang memainkan ritmis tertentu secara staccato yang menimbulkan kesan semangat dan gagah, filler yaitu memainkan rangkaian melodi pada bagian kosong (tidak ada melodi lagu) dengan beberapa teknikseperti canon, unisono, trill, kemudian blocking note yang membentuk wilayah akor yang dimainkan, dan melody note. Hadirnya aransemen woodwind ansambel ini menjadi nilai plus bagi penampilan Orkes Keroncong Gita Puspita dan menjadi pembeda dari orkes keroncong yang lain sehingga menjadi ciri khas/identitas Orkes Keroncong Gita Puspita yang senantiasa dinantikan oleh Tegal sehingga musik keroncong di Tegal tetap berkelanjutan.

\section{Referensi}

Asriyani, N., \& Rachman, A. (2019). Enkulturasi Musik Keroncong oleh O.K Gema Kencana Melalui Konser Tahunan di Banyumas. In Musikolastika: Jurnal Pertunjukan dan Pendidikan Musik (Vol. 1, Issue 2, pp. 74-86). Universitas Negeri Padang (UNP). https://doi.org/10.24036/musikolastika.v1i2.27 
Fauziah, Z., \& Rachman, A. (2017). Aransemen Vokal Sebagai Identitas O.K. Congrock 17 di Semarang. Jurnal Seni Dan Budaya, 1(2), 63-69. http://jurnal.unimed.ac.id/2012/index.php/GDG

Ferzacca, S. (2015). Learning How to Listen : Kroncong Music in a Javanese Neighborhood Learning How to Listen. The Senses and Society, 8927(October). https://doi.org/10.2752/174589206778476207

Ferzacca, S., Hickey, M., \& Bunnell, T. (2012). Deep Sound, Country Feeling : Kroncong Music in a Javanese Neighbourhood. 180.

Ganap, V. (2006). Pengaruh Portugis Pada Musik Keroncong (portuguese influence to Kroncong Music). Harmonia, VII(4), 1-8. https://doi.org/10.15294/harmonia.v7i2.753

Ganap, V. (2011). Krontjong Toegoe. Badan Penerbit Institut Seni Indonesia Yogyakarta.

Ganap, V. (2020). Krontjong Toegoe: Asal-usul Musik Keroncong (I. Suhanda (ed.)). PT Kompas Media Nusantara.

Harmunah. (1987). Musik Keroncong: Sejarah, Gaya, dan Perkembangan. Pusat Musik Liturgi. Harmunah. (1996). Musik Keroncong. Pusat Musik Liturgi.

Henry, N. (2017). Diskursus Pelestarian Seni Budaya Keroncong. Sosiologi Dilema, 32(2), 5263.

Iqbal, M. N., Aesijah, S., \& Rachman, A. (2020). Bentuk Komposisi Musik Tradisional Balo-Balo Grup Kampung Tirang di Kecamatan Tegal Barat Kota Tegal. Jurnal Seni Musik, 9(2).

Kodijat, L. (1986). Tangga Nada dan Trinada. Djambatan.

Kodijat, L. (2004). Istilah-istilah Musik. Djambatan.

Leon, S. (1979). Structure and Style: The Study and Analysis of Musical Forms (Expanded E). Warner Bros. Publications.

Muhammad, Y. R., \& Rachman, A. (2020). Media Sosial Sebagai Sarana Promosi Karya Musik Di Era Industri 4.0 (Studi Kasus Pada Band Sendau Gurau Di Semarang). Musikolastika: Jurnal Pertunjukan Dan Pendidikan Musik, 2(1), 23-30. https://doi.org/10.24036/musikolastika.v2i1.35

Prasetyo, B., \& Trisyanti, U. (2019). Revolusi Industri 4.0 dan Tantangan Perubahan Sosial. IPTEK: Journal of Proceedings Series, 5, 22-27. https://doi.org/https://dx.doi.org/10.12962/j23546026.y2018i5.4417

Prier, K. E. (2005). Bentuk Musik (S. Sunarto \& U. Utomo (eds.); Edisi Satu). PT Balai Pustaka (Persero).

Qurrata A'yun, W., \& Rachman, A. (2019). "Keroncong in Jamaican Sound" Sebuah Inovasi dalam Melestarikan Musik Keroncong di Bandung. Jurnal Seni Musik Unnes, 8(1).

Rachman, Abdul; Lestari, W. (2012). Bentuk Aransemen Musik Keroncong Asli Karya Kelly Puspito Dan Relevansinya Bagi Remaja Dalam Mengembangkan Musik Keroncong Asli. Catharsis: Journal of Arts Education, 1(2).

Rachman, A. (2013a). Bentuk dan Analisis Musik Keroncong Tanah Airku Karya Kelly Puspito. 
HARMONIA - Jurnal Pengetahuan Dan Pemikiran Seni, 13(1), 69-77.

Rachman, A. (2013b). Bentuk Dan Analisis Musik Keroncong Tanah Airku Karya Kelly Puspito. Vol. 13(No. 1), 70.

Rachman, A., \& Pribadi, S. E. (2019). Kroncong Music in Semarang: A Process of Enculturation. IJAL: IC ADRI 23- ICUTK, June Pattaya - Thailand, 4(2), 1-9. https://drive.google.com/drive/folders/1vIRHgCoi07hYzJnY3T9ywS8VjWSJdB8d

Rachman, A., \& Utomo, U. (2018). "Sing Penting Keroncong": Sebuah Inovasi Pertunjukkan Musik Keroncong di Semarang. Jurnal Pendidikan Dan Kajian Seni, 3(1).

Rachman, A., \& Utomo, U. (2019). The Rhythm Pattern Adaptation of Langgam Jawa in Kroncong. Advances in Social Science, Education and Humanities Research, Volume 276 2nd International Conference on Arts and Culture (ICONARC 2018), 276(Iconarc 2018), 99-101.

Rachman, A., Utomo, U., \& Asriyani, N. (2019). Penciptaan lagu keroncong berbasis kearifan lokal di kota semarang. JPKS: Jurnal Pendidikan Dan Kajian Seni, 4(2), 101-114.

Ramadhani, F. A., \& Rachman, A. (2019a). Resistensi Musik Keroncong di Era Disrupsi: Studi Kasus pada O.K Gita Puspita di Kabupaten Tegal. Musikolastika: Jurnal Pertunjukan Dan Pendidikan Musik, 1(1), 41-51.

Ramadhani, F. A., \& Rachman, A. (2019b). Resitensi Musik Keroncong di Era Disrupsi: Studi Kasus Pada O.K Gita Puspita di Kabupaten Tegal. In Musikolastika: Jurnal Pertunjukan dan Pendidikan Musik (Vol. 1, Issue 1, pp. 41-51). Universitas Negeri Padang (UNP). https://doi.org/10.24036/musikolastika.v1i1.18

Setiyawan, K. B. (2018). Keroncong : Musik dan Identitas. September, 0-17.

Soeharto, D. (1996). Serba-Serbi Musik Keroncong. Musika.

Sulestiyorini, C. R. (2013). Kreativitas dan Fungsi Musik Keroncong (Studi Kasus Pada Grup Musik Keroncong Kasela Bergema). Universitas Negeri Semarang.

Wijayadi, A. S. (2007). Mendayung di antara tradisi dan modernitas: sebuah penjelajahan ekspresi budaya terhadap musik keroncong. Hanggar Kreator. 